\title{
Application of numerical simulation to determine ability of air used in MQL method to clean grinding wheel active surface during sharpening of hob cutters
}

\author{
Wojciech Stachurski ${ }^{1}$ D Jacek Sawicki ${ }^{2}$ D $\cdot \mathrm{Krzysztof} \mathrm{Krupanek}^{2}$ (D) Krzysztof Nadolny $^{3}$ (D)
}

Received: 18 May 2020 / Revised: 1 June 2020 / Accepted: 4 June 2020 / Published online: 6 July 2020

(c) The Author(s) 2020

\begin{abstract}
This article presents the results of experiments concerning a computational fluid dynamics (CFD)/numerical analysis of the flow of air in the grinding zone during the sharpening of the face surface of hob cutters while using the MQL method. The carrying out of a simulation allows one to determine the influence of various settings of the angle of the spray nozzle on the amount of air directly reaching the zone of contact of the grinding wheel with the workpiece, as well as the grinding wheel active surface (GWAS). In the numerical analysis, the 'SST $k$ - $\omega$ ' model available in the Ansys CFX program was used, and to which the Kato and Lander's modification was applied. With the aim of verifying the results obtained from the basis of the numerical simulations, experimental testing was conducted. As a verification parameter, the percentage rate of grinding wheel clogging was used. The measurement of clogging was conducted by the optical method taking microscopic images of the grinding wheel active surface (GWAS) and then analysing it which the use of digital processing and image analysis. As a result of the numerical simulations, it was confirmed that the greatest effectiveness in delivering air to the contact zone of the grinding wheel with the workpiece being machined was achieved by setting the nozzle at the lowest of the angles tested $\left(90^{\circ}\right)$. At the same time, the greatest efficiency in delivering air to the grinding wheel active surface was achieved by setting the nozzle at the largest of the angles tested $\left(90^{\circ}\right)$. The experimental tests allowed one to state that the change in the inclination of the spray nozzle does not significantly influence the effectiveness of chip removal from the surface of the intergranular spaces of the grinding wheel. By setting the nozzle at a $90^{\circ}$ angle, wall shear stresses $\tau_{w}$ have a decisive influence on cleaning the GWAS, while at an angle of $30^{\circ}$ the cleaning function is taken on by air being delivered directly into the contact zone of the grinding wheel with the face surface of the hob cutter being sharpened. A comparison of the percentage rates of grinding wheel clogging obtained from using the flood method (WET), as well as the MQL method, indicates the insufficient cleaning ability of the MQL method. A solution to this problem may be the application of additional cleaning nozzles employing streams of compressed air (CA) or cold compressed air (CCA).
\end{abstract}

Keywords Hob cutters $\cdot$ Grinding process $\cdot$ Coolant $\cdot \mathrm{MQL} \cdot$ Numerical simulation $\cdot$ CFD $\cdot$ Grinding wheel clogging

Krzysztof Nadolny

krzysztof.nadolny@tu.koszalin.pl

1 Institute of Machine Tools and Production Engineering, Lodz University of Technology, Stefanowskiego 1/15, 90-924 Lodz, Poland

2 Institute of Materials Science and Engineering, Lodz University of Technology, Stefanowskiego 1/15, 90-924 Lodz, Poland

3 Department of Production Engineering, Faculty of Mechanical Engineering, Koszalin University of Technology, Racławicka 15-17, 75-620, Koszalin, Poland

$\begin{array}{ll}\text { Abbreviations } \\ \text { CFD } & \text { Computational fluid dynamics } \\ \text { CMOS } & \text { Complementary metal-oxide-semiconductor } \\ \text { GWAS } & \text { Grinding wheel active surface } \\ \text { HRC } & \text { Hardness in Rockwell C scale } \\ \text { LED } & \text { Light-emitting diode } \\ \text { RANS } & \text { Reynolds-averaged Navier-Stokes equations } \\ \text { SST } & \text { Shear stress transport turbulence model } \\ \text { WET } & \text { Flood method using water emulsion as coolant } \\ a & \text { Machining allowance (mm) } \\ a_{e} & \text { Working engagement (mm) } \\ m & \text { Module (mm) } \\ \dot{m}_{i n} & \text { Mass flow of air on inlet surface into fluid } \\ & \text { domain }(\mathrm{kg} / \mathrm{s})\end{array}$

Abbreviations

CMOS Complementary metal-oxide-semiconductor

GWAS Grinding wheel active surface

HRC Hardness in Rockwell C scale

LED Light-emitting diode

RANS Reynolds-averaged Navier-Stokes equations

SST Shear stress transport turbulence model

WET Flood method using water emulsion as coolant

a Machining allowance ( $\mathrm{mm})$

$a_{e} \quad$ Working engagement $(\mathrm{mm})$

$m \quad$ Module (mm)

domain $(\mathrm{kg} / \mathrm{s})$ 


\begin{tabular}{|c|c|}
\hline$\dot{m}_{\text {out }}$ & $\begin{array}{l}\text { Mass flow of air on outlet surface into fluid } \\
\text { domain }(\mathrm{kg} / \mathrm{s})\end{array}$ \\
\hline$n_{s}$ & Grinding wheel rotational speed (rpm) \\
\hline$P_{\tau}$ & Area of wall shear stress $\left(\mathrm{mm}^{2}\right)$ \\
\hline$Q_{d}$ & Diamond dresser mass $(\mathrm{kt})$ \\
\hline$v_{s}$ & Grinding wheel peripheral speed $(\mathrm{m} / \mathrm{s})$ \\
\hline$v_{w}$ & Workpiece peripheral speed $(\mathrm{m} / \mathrm{min})$ \\
\hline$z_{h}$ & Number of cutting blades (hob cutter) \\
\hline$Z_{\%}$ & Percentage rate of grinding wheel clogging $(\%)$ \\
\hline$\alpha$ & Pressure angle $\left({ }^{\circ}\right)$ \\
\hline$\varepsilon$ & $\begin{array}{l}\text { Angle of nozzle inclination during air delivery } \\
\left({ }^{\circ}\right)\end{array}$ \\
\hline$\eta_{w s}$ & $\begin{array}{l}\text { Efficiency of system delivering air directly into } \\
\text { the grinding zone }\end{array}$ \\
\hline & Wall shear stress $(\mathrm{Pa})$ \\
\hline & Maximum wall shear stress $(\mathrm{Pa}$ \\
\hline
\end{tabular}

\section{Introduction}

One of the basic functions of coolant in the grinding process is rinsing away chips in the work zone, along with cleaning the grinding wheel itself [1]. This function is crucially important in view of the fact that the grinding wheel active surface (GWAS) influences both the course and the effects of the grinding process determined, among other things, by the geometric structure of the surface, microhardness, as well as the state of stress in the workpiece surface layer [2-4]. In this context, one of the most undesirable phenomena occurring during grinding is the appearance of clogging of the intergranular spaces taking place on in the area of the active grinding surface. A proliferation of clogging causes a reduction in the cutting ability of the grinding wheel, a reduction in efficiency, an increase in grinding force, as well as an increase in friction and consequently temperature, which leads to premature wearing of the tool. A too-high temperature also encourages the occurrence of grinding defects, such as burns on the workpiece surface [5].

One of the most effective ways to remove chips from the grinding zone, as well as to clean the grinding wheel, is the application of the conventional flood method (WET) with the use of water oil emulsion. This method is still commonly used in industrial practice $[6,7]$. Through appropriately selected conditions for the use of water oil emulsions, such as the nominal flow rate and the angular setting of the nozzle in regard to the GWAS, the flood method facilitates the effective removal of impurities from the grinding zone, significantly limiting the occurrence and increase of clogging on the grinding wheel active surface [8-10].

It should, however, be remembered that the high level of effectiveness of the WET method is connected with the necessity of delivering high rates of coolant into the grinding zone. From a technical point of view this is a fundamental disadvantage of this method, considering that only a small part of the volume of the emulsion reaches the area of contact between the grinding wheel and the material being machined [9]. Moreover, the necessity to buy, clean, regenerate and use coolant fluids significantly raises manufacturing costs [11-13].

Taking the above into account, it is aimed to completely eliminate or reduce expenditure on coolant fluids. During recent years, this aim has been further strengthened due to environmental reasons and the necessity of adhering to ever more strict rules related with environmental protection and workers' health and safety $[14,15]$

In this context, one of the most frequently used ways of significantly reducing the amount of coolant being delivered into the grinding zone is the employment of the minimum quantity lubrication method, known by the acronym MQL $[7,8,16]$. The MQL method is based on the continuous production of an oil mist and delivering it direct into the grinding zone, most often to the grinding wheel active surface. The flow of lubricating agent is facilitated by a transporting agent, namely a stream of compressed air [17], also fulfilling, to a small degree, the function of a coolant. The literature indicates that the MQL lubricating agent is delivered in the amount of $10-500 \mathrm{ml} / \mathrm{h}$ [7, 14, 18-23]. In comparison, water oil emulsions, when used in the flood method, are used in amounts of over $120,000 \mathrm{ml} / \mathrm{h}$, although during grinding this amount, depending on the type of process, can reach from 300,000 to $1,200,000 \mathrm{ml} / \mathrm{h}$. Synthetic esters or fatty alcohols are most often used as a lubricating agents. For some time now, due to environmental reasons, vegetable oils have also been used as a lubricating agent in the MQL method [15, 23-25]. However, a major limitation in the use of vegetable oils is their high cost in comparison with synthetic and mineral oils [26]. According to Madanhire and Mbohwa [27] vegetable oils are up to eight times more expensive when compared with machining fluids based on mineral oils.

One should remember that, alongside the advantages of the MQL method related with its good lubricating properties, it possesses the disadvantage of a lack of sufficient cooling properties over a broad range of variables in the grinding process when compared with the traditional flood method $[28,29]$. The cause of this state of affairs is due to the small amount of coolant delivered into the grinding zone and, additionally, the low heat storage capacity of the oil and air $[29,30]$. For this reason, during recent years intensive research has been conducted on improving the effectiveness of cooling and lubrication in the MQL method. In this regard, research on the use of nanofluids, as well as joining the MQL method with cryogenic cooling, along with delivering an additional stream of cooled air, is undergoing particularly intensive development [14, 15, 19, 20, 28, 31-37]. 
In the case of nanofluids, a serious limitation in industrial applications is the significant increase in viscosity in regard to the base oil [38-40]. A further obstacle in the common industrial use of nanofluids is the necessity to maintain a uniform and stable suspension of nanoparticles, as well as their even distribution throughout the base oil, along with the necessity to lower the quite high cost of using nanoparticles [41, 42]. In the case of employing cryogenic cooling, the disadvantage of such a solution is the cost of the special system delivering the cryogenic agent to the machining zone, greater than in the case of a conventional system, as well as the greater cost of purchasing $\mathrm{LN}_{2}$ in comparison with conventional coolant fluids.

Despite the disadvantages listed above, mainly those of a financial nature, the application of MQL methods, along with it various improvements (such as: vegetable oil, nanofluids, cryogenic cooling), is a desirable solution from an environmental point of view. Moreover, due to technological reasons, the MQL method, when used in appropriate machining conditions, produces results comparable with those gained from the flood method (WET), while, in particular machining conditions, the results gained from the MQL method are even better [13, 14]. Examples of such experiments concern, among other things: surface roughness [18, 28, 36]; microhardness [22, 33, 43, 44]; residual stress [21, 22, 44]; grinding forces [33, 45, 46]; grinding temperature $[45,47]$; specific grinding energy and $G$ ratio $[33,36,37,43,46]$.

However, attention should be paid to the fact that up to now research studies have concentrated on ensuring the effective lubrication and cooling of the grinding zone and determining the impact of using the MQL method on the machined surface quality (roughness, microhardness, stress) and the parameters of the grinding process (grinding forces, grinding temperature). In the research studies available there is a lack of information on the subject of the ability of the MQL method to achieve a longer period of grinding wheel life, the cleaning of its active surface and removal of impurities from the grinding zone. In focusing on the high significance of this function of a coolant fluid on the course and results of the grinding process, the authors of this article present research on this question. This research was conducted during the grinding of the face surface of hob cutters. It was acknowledged that the basis for assessing and optimising the conditions for delivering the coolant in the MQL method would be first conducting and then analysing numerical simulations of air flow in the grinding zone.

It must be emphasised that carrying out flow simulations is a labour-intensive and time-consuming task, which results in, among other things, preparing a geometric model and computational grid, setting the boundary and initial conditions, as well as running simulations based on an appropriate flow model. The issues connected with this are described in the Sect. 2 of this work. In the numerical analysis, the SST $k$ - $\omega$ model, available in the Ansys CFX program, was employed and Kato and Launder's modifications applied to it. The results gained on the basis of the developed numerical model are presented in Sect. 3. On the basis of the results, the efficiency $\eta_{w s}$ of the system delivering air directly into the grinding zone was determined, meaning the parameter determining the relationship between the amount of air delivered by the nozzle into the grinding zone and the amount of air delivered directly into the contact zone of the grinding wheel with the hob cutter. In addition, the value of wall shear stress $\tau_{w}$ occurring on the conical surface in the area of the grinding wheel active surface was also determined, as well the area of wall shear stress $P_{\tau}$ on which these stresses have an impact.

With the aim of verifying the results of the simulation gained, experimental tests were conducted and which are described in Sect. 4. As a parameter verifying the effectiveness of air delivery into the grinding zone, the amount of clogging occurring on the GWAS was chosen. It was assumed that this amount would be defined as the percentage rate of grinding wheel clogging $Z \%$. This rate was determined on the basis of GWAS microscopic image analysis. This method has also been used by other researchers in a similar way [48, 49], as well as by the authors [10].

It worth emphasising that in the scientific-technical literature there is a lack of complex research and studies concerning the use of coolant during the sharpening of hob cutters employing of the MQL method. The small number of works available only concentrate on describing experimental tests $[35,50]$. Moreover, as the research studies in the field described in this article constitute something new and not dealt with until now, this work is important both for scientific and industrial reasons.

\section{Numerical simulation of the flow of coolant fluid delivered by minimum quantity lubrication (MQL) in the process of grinding hob cutters' face surface}

\subsection{CAD 3D models}

The numerical simulations described in this article were conducted with the use of a CAD 3D model of real elements occurring in the hob cutter sharpening process (Fig. 1). The process depends on grinding the face surface of the hob cutter on a special tool grinder. During the grinding of a hob cutter (1) it is: fixed in the cutter arbour (2); moves together with the grinder table at speed $v_{w}$ in regard to the grinding wheel (3); rotating at speed $n_{s}$. The machining allowance is taken as a result of the reciprocal movement of the grinding wheel and the hob cutter in 


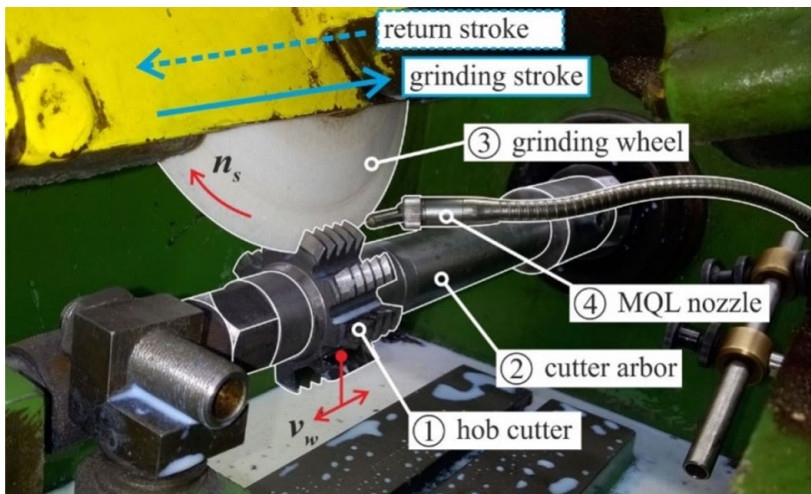

Fig. 1 View of the machining area during the process of hob cutter sharpening

the following cycles which are comprised of alternating grinding and return strokes. The coolant is delivered into the grinding zone by a single nozzle, in this case by an MQL nozzle (4), spraying an oil-mist as part of the MQL method.

The assumptions made in creating the CAD 3D model used for the requirements of the numerical simulation are presented in Table 1.

The module value $m$ of the hob cutter was chosen as an upper value in regard to the hob cutter modules most frequently employed in the motor industry in the production of cars. In practice, this allowed one to produce the toughest working conditions resulting in the longest maximum line of contact of the abrasive grains of the grinding wheel active surface with the machined surface.

In Fig. 2, a 3D geometric model is presented, as well as a way to generate the oil-mist in the MQL nozzle used in the described experiments. The oil and water are delivered to the nozzle outlet through separate channels. The stream of oil is sprayed at the nozzle outlet by a stream of air creating an oil-mist. The mist made in this way is (a)

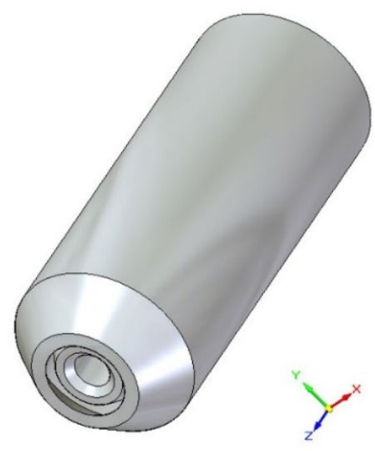

(b)

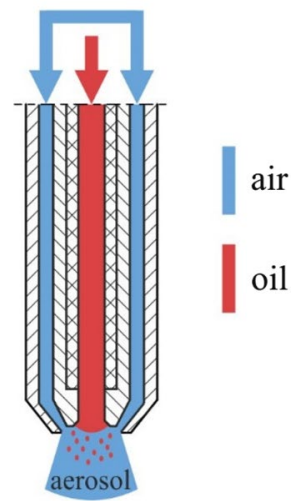

Fig. 2 Spray nozzle used in the MQL method. a CAD 3D model, $\mathbf{b}$ longitudinal cross-section of CAD 3D model

directed into the machining area as a result of setting the spray nozzle appropriately.

\subsection{CAD 3D model of system and delivery of cooling and lubrication agent in the MQL method}

Before attempting to carry out numerical simulations, the created CAD 3D models were reciprocally placed in a way corresponding to the real settings of the reproduced parts during the sharpening process. A CAD 3D model of the system was created in this way (Figs. 3 and 4).

As shown in Fig. 3, the coolant fluid in the form of an oil-mist is delivered into the grinding zone with the aid of nozzle (3), on the right-hand side the hob cutter (2) on a piece of an MQL grinding wheel active surface (1). The $\mathrm{MQL}$ area is situated between line $\mathrm{X}$ comprising the line of contact of the apical cutting edge of the hob cutter with the grinding wheel and an imaginary line $\mathrm{Y}$ situated parallel to line $\mathrm{X}$ at a distance of $25 \mathrm{~mm}$ from it (Fig. 3). Such a location of the MQL area results from a review of the literature which indicated that the oil-mist should be sprayed onto the

Table 1 Parameters of CAD 3D model

\begin{tabular}{ll}
\hline CAD 3D model & \\
\hline Part & Parameter \\
\hline Hob cutter & Solid hob cutter for hobbing cogwheels in accordance with ISO 53 and ISO 54, \\
& Module $m=3 \mathrm{~mm}$, \\
& Pressure angle $\alpha=20^{\circ}$, \\
& Number of cutting edges $z_{h}=9$, \\
& Normal ground profile, \\
& Geometrical dimensions selected according to PN-ISO 4468:1999, \\
& accuracy class B (according to PN-ISO 4468:1999) \\
& Dish grinding wheel - type 12 according to PN-ISO 525:2001, \\
& Dimensions: 200/90×20/2 $\times 32$ (according to the Norton company catalogue) [51] \\
& Single two-channel nozzle with an oil-mist generator as an external fitting MKS- \\
Grinding wheel & G100 MicroJet company (Germany) [52] \\
MQL nozzle &
\end{tabular}




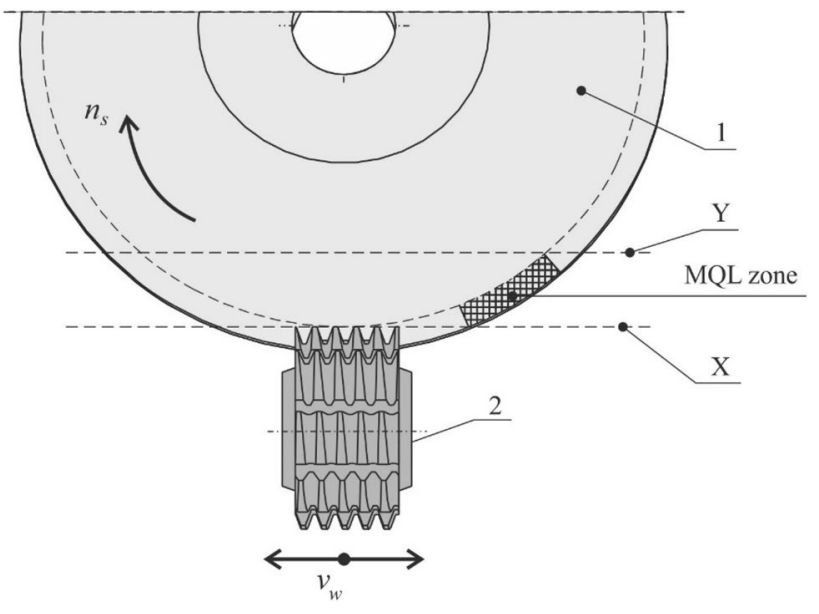

Fig. 3 Placement of the area on the grinding wheel active surface onto which the oil-mist is directed (MQL area): 1-grinding wheel; 2hob cutter; $\mathrm{X}$-line of contact of apical cutting edge of the hob cutter with grinding wheel; $\mathrm{Y}$-imaginary line parallel to line $\mathrm{X}$

grinding wheel active surface (GWAS) as close as possible to the contact zone of the grinding wheel and the object being machined. The placement of this area in the manner shown in Fig. 3 takes into account the limitations (collisions) introduced by reciprocal movement of the grinding wheel and the hob cutter during machining.

The axis of the nozzle (Fig. 4) is inclined towards line A, indicated by the tapering of the grinding wheel at a degree of $90^{\circ}$ (Fig. 4), and then at angle $\varepsilon$ in relation to line B (Fig. 4c), tangential to the GWAS and simultaneously cutting line A at an angle of $90^{\circ}$ (Fig. 4). As shown in Fig. 4, in the experiments four settings of angle $\varepsilon$ were used, namely: $30^{\circ}, 45^{\circ}, 60^{\circ}$ and $90^{\circ}$. Due to technical limitations regarding the settings, the angular inclination of the spray nozzle generating the oil-mist in regard of the grinding wheel active surface may be no less than $30^{\circ}$. In addition, the nozzle outlet (3) is placed at a distance of $15 \mathrm{~mm}$ from the GWAS. The grinding wheel, rotating in a clockwise direction, carries with it the oil-mist and directs it into the contact zone of the active abrasive grains with the hob cutter.

\subsection{Numerical simulation of air flow in MQL method}

\subsubsection{Model and computational grid}

The aim of the conducted simulation experiments was to determine the ability of the air used in the MQL method during hob cutter sharpening in cleaning the GWAS. Due to this, the numerical simulation of the cooling and lubrication agent was limited to the delivery of just air, without the involvement of oil. The remaining conditions for delivering machining fluids did not undergo any change.
The following should be listed as the most important particular aims of the numerical simulations conducted:

(1) Indentifying the parameter determining the relationship between the amount of air delivered by the nozzle to the grinding zone with the amount of air delivered directly to the contact zone with the hob cutter. It is assumed that this parameter is to be defined as the effectiveness of the air delivery system by use of the MQL method;

(2) identifying the value of wall shear stresses $\tau_{w}$ occurring on the surface of a tapered grinding wheel in the area of the grinding wheel active surface as result of delivering air by use of the MQL method;

(3) determining the area of wall shear stress $P_{\tau}$ on which there is an impact of shear stresses $\tau_{w}$.

During the course of the experiments the flow of compressed air was simulated which, following its exit from the nozzle, hit the grinding wheel active surface rotating at the grinding wheel rotational speed $n_{s}$, and then, as a result of the rotation of the grinding wheel, was delivered into its contact zone with the hob cutter. The area in which the flow of air was simulated was determined by the fluid domain, placing it between the parts of the 3D model of the system and adapting it to the shape of the grinding wheel, hob cutter and nozzle ends (Fig. 5).

Before attempting to conduct the simulation, the fluid domain was optimised, creating hexagonal grid elements whose regular shape facilitate the obtaining of correct results in the numerical simulation. Particular emphasis is placed on grid integrity and the appropriate density of the inflation layer in the place where the air hits the surface of the rotating grinding wheel. The appearance of fluid domain grids optimised for the requirements of the simulation is shown in Fig. 6. Depending on the angle of the nozzle configuration, the number of nodes in the discrete model ranged from $1,082,908$ to $1,599,846$ and the number of elements from $1,085,411$ to $1,552,138$. Detailed values for each discrete model were shown in Table 2.

\subsubsection{Boundary and initial conditions}

Numerical simulations for determining efficiency $\eta_{w s}$, wall shear stresses $\tau_{w}$, and areas of wall shear stress $P_{\tau}$, were carried out for four angular settings of the nozzle. Angle $\varepsilon$ was applied ranging through $30^{\circ}, 45^{\circ}, 60^{\circ}$ and $90^{\circ}$ (Fig. 4). It was assumed that the surface which served for determining which part of the nominal output of the air came through the outlet surface from the fluid domain would be located under the hob cutter tooth as indicated in Fig. 7.

It should be pointed out here that due to the requirements of the described simulations assumptions were made that the hob cutter and the grinding wheel were 
Fig. 4 Angular placement of the nozzle delivering the oil-air mist (MQL) in regard to the grinding wheel active surface. a general view, $\mathbf{b}$ setting of the MQL nozzle in regard to line A, c setting of the MQL nozzle in regard to line $\mathrm{B} ; 1$-grinding wheel; 2-hob cutter; 3-MQL nozzle; A-line indicated by tapering of the grinding wheel; B-line tangential to the grinding wheel active surface (a)

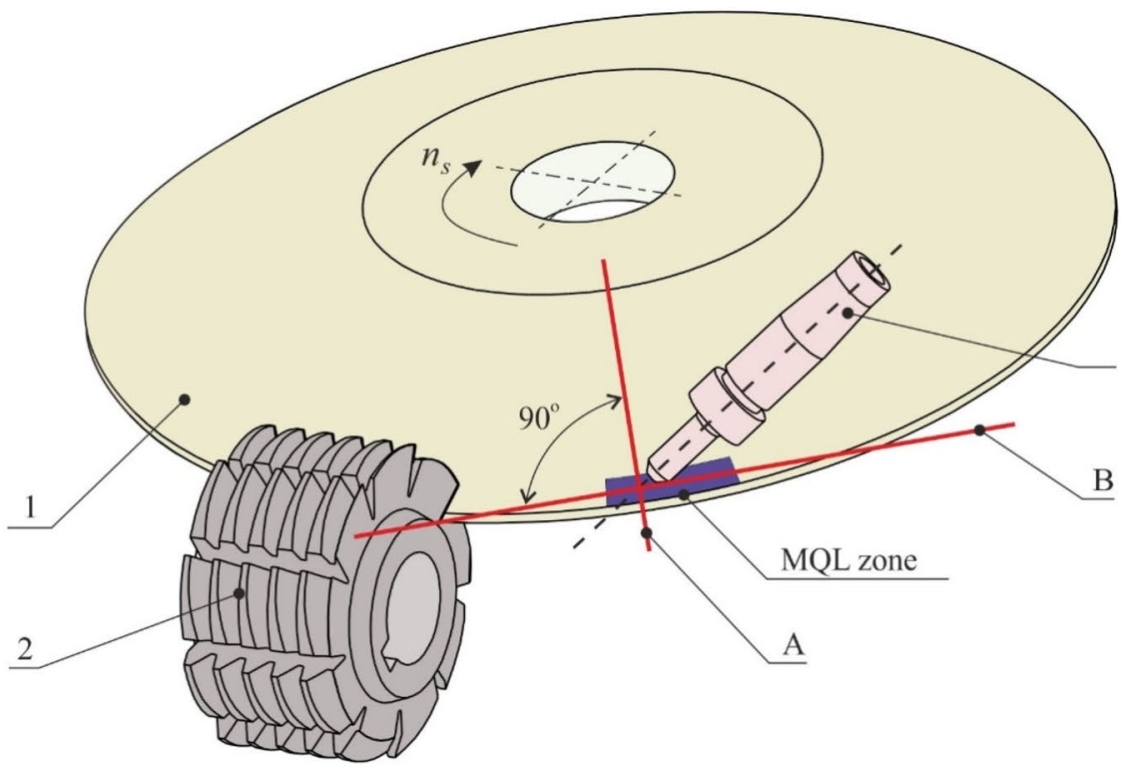

(b)

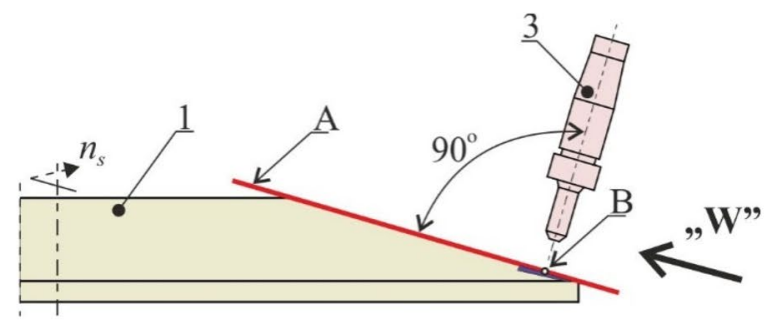

(c)

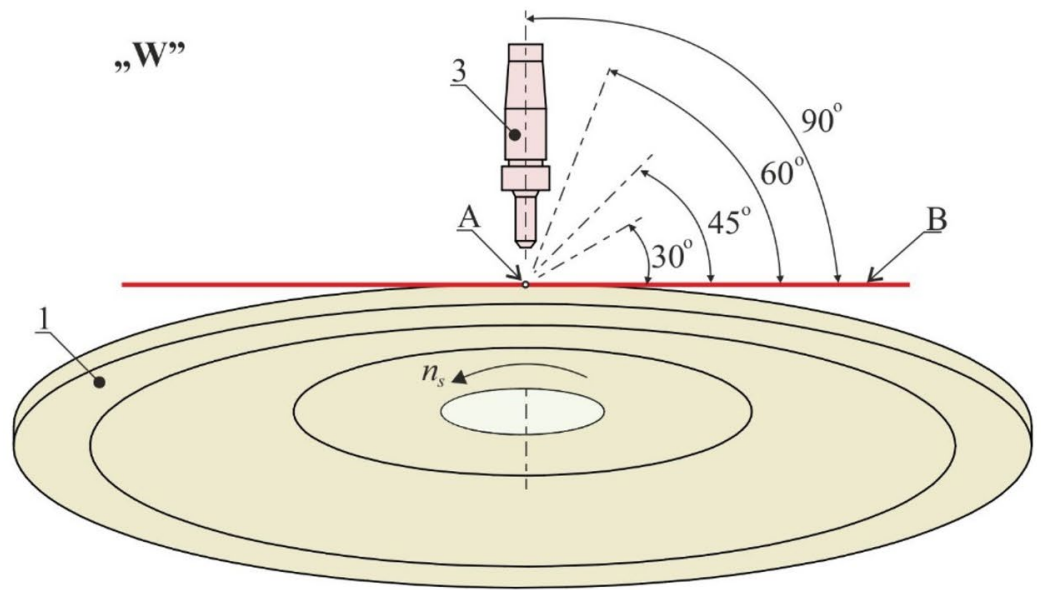

stationary in regard to each other, apart from the rotation of the grinding wheel with a rotational speed of $n_{s}=2950 \mathrm{rpm}$. This simplification is a result of the fact that during machining the length of the line of contact between the grinding wheel and the hob cutter (rack shape) was changing in a continuous manner and, following on from this, the outlet surface from the fluid domain would have also undergone dimensional changes. In the view of the authors, the lack of this simplification would have led to an unnecessary lengthening of the duration of the numerical simulation.
Finally, it was assumed to determine efficiency $\eta_{w s}$ as the relationship of the mass flow $\dot{m}_{\text {in }}$ of air on the inlet surface into the fluid domain with the mass flow $\dot{m}_{\text {out }}$ of air on the outlet surface from the fluid domain, which is described by the Eq. (1):

$\eta_{w s}=\frac{\dot{m}_{\text {in }}}{\dot{m}_{\text {out }}}$.

The numerical simulation was conducted using the Ansys CFX 2019 program. The boundary and initial conditions were defined as: 


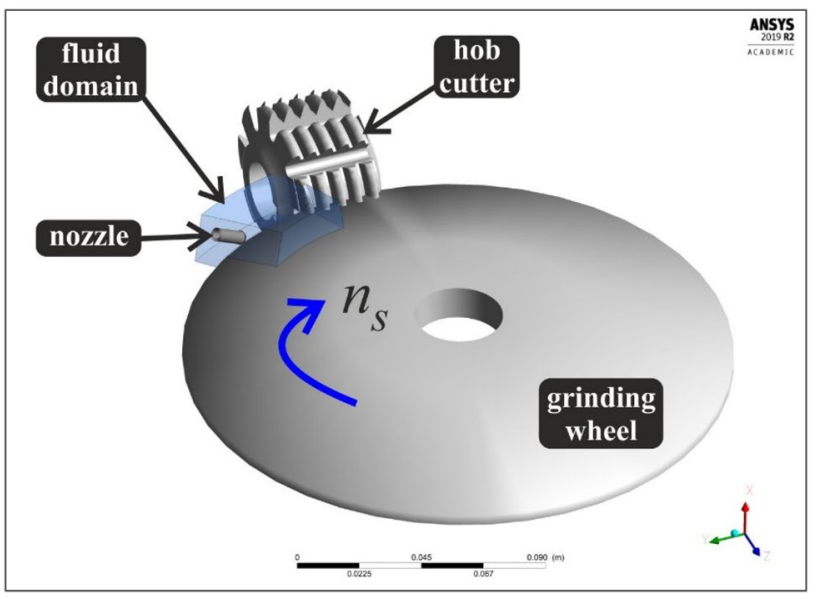

Fig. 5 Location of fluid domain in 3D model of air delivery system in MQL method

- Medium: air (in the CFX program the air model used ideal gas);

- Air temperature: $20^{\circ} \mathrm{C}$ (ambient room temperature);

- Inlet velocity: $30 \mathrm{~m} / \mathrm{s}$;

- Rotational speed of the grinding wheel tapered surface:

$-n_{s}=2950 \mathrm{rpm}$,

- rotating clockwise.

Due to the requirements of the simulation it was assumed that the absolute barometric pressure reached $1013 \mathrm{hPa}$. In regard to this, the pressure value on the surface of the fluid domain was defined as $0 \mathrm{~Pa}$.

(a)

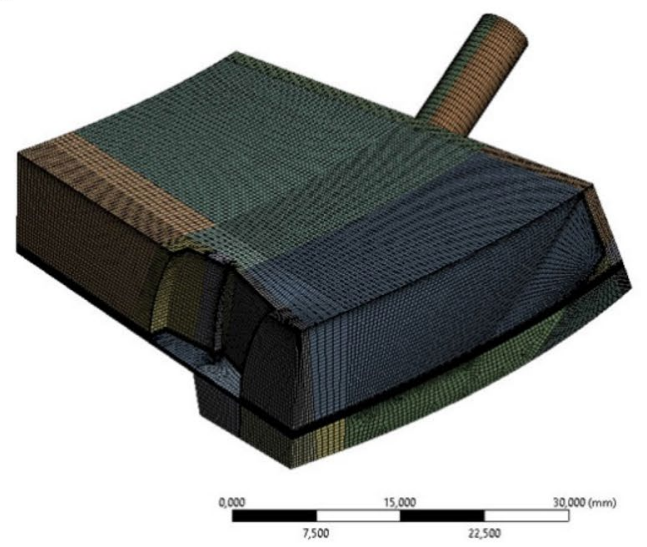

(b)

\subsubsection{Turbulence model and modification of the production term}

In this study, the SST $k-\omega$ model, available in the Ansys CFX program was employed [53]. Kato and Launder's modifications were applied to the SST $k-\omega$ model itself [54]. This model is a hybrid combining the best properties of the $k-\omega$ and $k$ - $\varepsilon$ models, as well as making it possible to introduce a term that limits over-production of turbulence kinetic energy in the areas of high-pressure gradients. In addition, $k-\omega$ equation models are used modelling the turbulence flow in the boundary layer. Due to the fact that the $k-\omega$ model is highly sensitive to the turbulent values in the free flow, it is substituted with the $k-\varepsilon$ model in the layers located further away from the wall. This model models turbulence in the free flow well and is also less sensitive to inlet conditions of a magnitude describing turbulence. The desired characteristics of both modules combine into one model, taking advantage of the fact that the standard $k-\varepsilon$ model may be transformed into equations for $k$ and $\omega$ due to the fact that $\omega$ is the appropriate dissipation of the kinetic energy of turbulence, thus $\omega=\varepsilon / k$. The equations of this model are then multiplied by a function which has a value of 1 in free flow and 0 at the wall, while the standard $k-\omega$ model equation is multiplied by the function $F_{1}$. The applied equation models are as follows:

- Turbulent kinetic energy:

$$
\frac{\partial(\rho k)}{\partial t}+\frac{\partial\left(\rho u_{j} k\right)}{\partial x_{j}}=-P-\beta^{*} \rho \omega k+\frac{\partial}{\partial x_{j}}\left[\frac{\left(\mu+\sigma_{k} \mu_{t}\right) \partial k}{\partial x_{j}}\right]
$$

- Dissipation of turbulent kinetic energy:

Fig. 6 Discreet model of fluid domain. a General view, b cross-section 
Table 2 Characteristics of conditions of simulations

\section{Software}

Assumptions

Simplifications

Geometric parameters of the model Finite Element Mesh parameters

\section{ANSYS R2 2019}

Only the rotational movement of the grinding wheel was taken into account

The air has the properties of an excellent gas

All walls were modeled as smooth

Feed movements were omitted in order to simplify the system kinematics and shorten the time of simulation calculations

Oil supply has been omitted to reduce simulation calculation time

The number of geometric variants of the simulation has been limited to four nozzle inclination angle settings $\varepsilon$ : $30^{\circ} ; 45^{\circ} ; 60^{\circ}, 90^{\circ}$

The influence of earth acceleration on the flow of factors in the system under consideration was omitted

Heat exchange has been omitted

The geometric parameters of the 3D CAD model are listed in Table 1

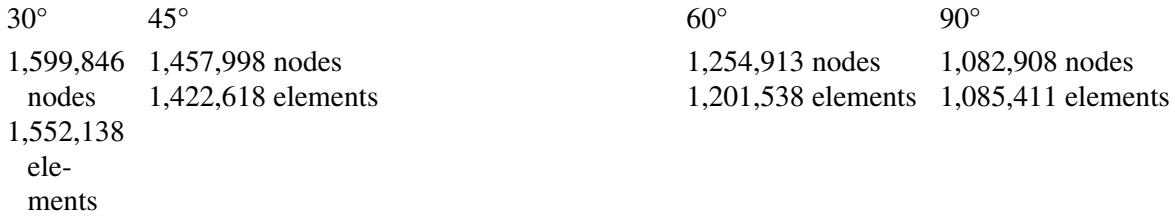

Conditions of the simulation process

Type of analysis: steady state

Continuous phase turbulence model: shear stress transport (SST) model with Kato and Launder's modification

Reference pressure value: $1013 \mathrm{hPa}$

Gravity influence model: no gravity influence

Degree of turbulence intensity: average (intensity 5\%)

Flow condition: subsonic

Air delivery speed: $30 \mathrm{~m} / \mathrm{s}$

Grinding wheel rotational speed: $n_{s}=2950 \mathrm{rpm}$, clockwise

Wall condition: no slip wall

Air temperature: $20^{\circ} \mathrm{C}$ (equal to ambient temperature)

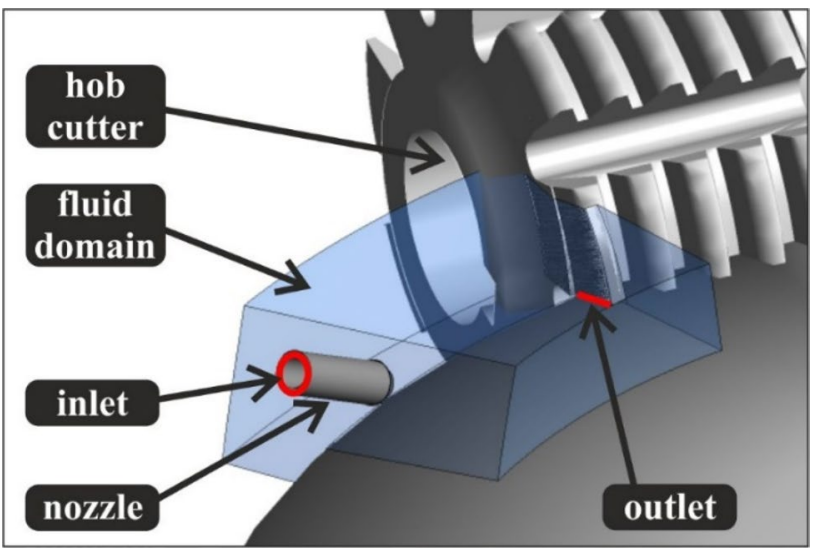

Fig. 7 Inlet and outlet surface from fluid domain (marked in red) (color figure online)

$$
\begin{aligned}
\frac{\partial(\rho \omega)}{\partial t}+\frac{\partial\left(\rho u_{j} \omega\right)}{\partial x_{j}}= & -\frac{\gamma}{v_{t}} P-\beta^{*} \rho \omega^{2}+\frac{\partial}{\partial x_{j}}\left[\left(\mu+\sigma_{\omega} \mu_{t}\right) \frac{\partial \omega}{\partial x_{j}}\right] \\
& +2\left(1-F_{1}\right) \frac{\rho \sigma_{\omega 2}}{\partial \omega} \frac{\partial k}{\partial x_{j}} \frac{\partial \omega}{\partial x_{j}}
\end{aligned}
$$

where:

- Turbulent viscosity:

$$
v_{t}=\frac{a_{1} k}{\max \left(a_{1} \omega, S F_{2}\right)}
$$

- Production term:

$$
P=\mu_{t} S S
$$

whereby: 


$$
S=\sqrt{\frac{1}{2}\left(\frac{\partial u_{i}}{\partial x_{j}}+\frac{\partial u_{j}}{\partial x_{i}}\right)^{2}} ;
$$

- Functions $F_{1}$ and $F_{2}$ :

$$
\begin{gathered}
F_{1}=\tanh \left(\arg _{1}^{4}\right), \arg _{1}=\min \left(\max \left(\frac{\sqrt{ } k}{0.09 \omega y}, \frac{500 v}{\omega y^{2}}\right), \frac{4 \rho \sigma \omega^{2} k}{\mathrm{CDk} \omega \mathrm{y}^{2}}\right) ; \\
F_{2}=\tanh \left(\arg _{2}^{2}\right), \arg _{2}=\max \left(2 \frac{\sqrt{ } k}{0.09 \omega y}, \frac{500 v}{y^{2} \omega}\right) ;
\end{gathered}
$$

- Constant coefficients:

$$
\begin{aligned}
& \sigma_{k 1}=0.85 \sigma_{\omega 1}=0.5 \quad \beta_{1}=0.075 \\
& \beta^{*}=0.09 \quad \kappa=0.41 \quad \gamma_{1}=\frac{\beta_{1}}{\beta^{*}}-\sigma_{\omega 1} \kappa^{2} \sqrt{\beta^{*}} ; \\
& \sigma_{\mathrm{k} 2}=1.0 \sigma_{\omega 2}=0.856 \beta_{2}=0.0828 \beta^{*}=0.09, \\
& \kappa=0.41 \gamma_{2}=\frac{\beta_{2}}{\beta^{*}}-\sigma_{\omega 2} \kappa^{2} \sqrt{\beta^{*}} .
\end{aligned}
$$

Kato and Launder's modification was applied to the SST $k-\omega$ model. The SST $k-\omega$ turbulence model has a tendency to overproduce artificially turbulence in the pile-up areas due to high $S$ values generated in these regions. Kato and Launder suggest substituting tangential stresses $S$ in the turbulence production equation with rotation $\Omega$, thus:

$P=\mu_{t} S \Omega$,

where:

$\Omega=\sqrt{\frac{1}{2}\left(\frac{\partial u_{i}}{\partial x_{j}}-\frac{\partial u_{j}}{\partial x_{i}}\right)^{2}}$.

\subsubsection{Wall shear stresses on the grinding wheel surface}

In view of the shear stresses in the boundary layer $[55,56]$ for a numerical simulation analysis focusing on the possibility of removing impurities from the grinding wheel active surface with a stream of air, wall shear stresses $\tau_{w}$ occurring on the tapering surface of the grinding wheel (wall) were used. This stress is described by the equation:

$\tau_{w}=\mu\left(\frac{\partial u}{\partial y}\right)_{y=0}$

where:

$\tau_{w}$ : wall shear stress on tapering surface of the grinding wheel (wall),

$\mu$ : dynamic viscosity, $u$ : speed on tapered surface of the grinding wheel (wall),

$y$ : distance from wall of the tapered surface of the grinding wheel.

Table 2 summarises the conditions of the numerical simulations performed.

\section{Results of numerical simulation of air flow in the hob cutter blade grinding zone by use of the MQL method}

\subsection{Efficiency $\eta_{w s}$ of the air delivery system}

Figure 8 shows the layout of the air flow streamlines in the fluid domain obtained as a result of numerical simulations for four angular settings of the nozzle, namely: $30^{\circ}, 45^{\circ}$, $60^{\circ}, 90^{\circ}$.

As may be observed in Fig. 8, decreasing the angle of inclination $\varepsilon$ in regard to the grinding wheel active surface causes that the lines representing the air flow streamlines are more concentrated and arrange themselves in a direction 'under the tooth' of the hob cutter (in accordance with the rotational direction of the grinding wheel). This causes that the greater part of the air streams reach the contact zone of the hob cutter with the grinding wheel resulting in lower losses as a consequence of multi-directional spraying of air from the site where it hits the grinding wheel, which occurs, for example, when the inclination of the nozzle is at $90^{\circ}$.

Confirmation of the above-described character of the impact of changes to the angle of inclination $\varepsilon$ on the directionality of the air streams are a result of efficiency $\eta_{w s}$, defining the relationship between the amount of air delivered by the nozzle into the grinding zone and the amount of air delivered directly into the contact zone of the grinding wheel with the hob cutter. The results are tabulated in Table 3 and presented in Fig. 9.

As the results from the data presented in Table 3 and Fig. 9 indicate, decreasing angle $\varepsilon$ causes an increase in the effectiveness of delivering air into the grinding zone expressed as efficiency $\eta_{w s}$. The greatest efficiency $\eta_{w s}$, meaning the most beneficial from a viewpoint of cleaning (and cooling) the grinding zone, was achieved by setting the nozzle at an angle of $\varepsilon=30^{\circ}$ in regard to the grinding wheel active surface. The numerical simulation indicated in this case that, although most of the stream of air, as a result of the occurrence of the air barrier phenomenon around the spinning grinding wheel, most of which did not reach the GWAS, was instead carried and directed straight into contact zone of the grinding wheel with the hob cutter.

Attention should be paid to a small difference between the efficiency rate obtained at the angles of $30^{\circ}$ and $40^{\circ}$, reaching almost $2 \%$. In practice, this means a large tolerance of the angular setting of the nozzle, which translates into 
(a)

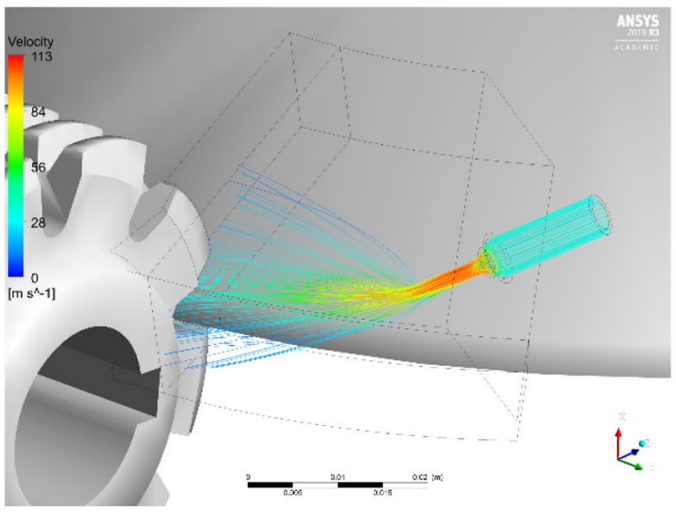

(c)

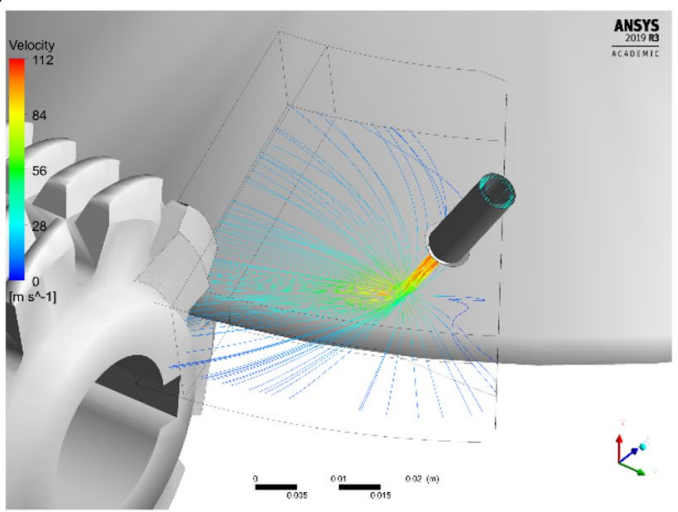

(b)

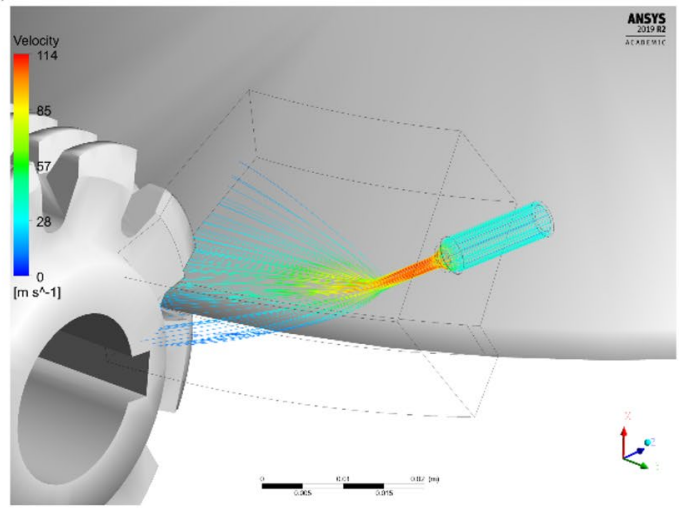

(d)

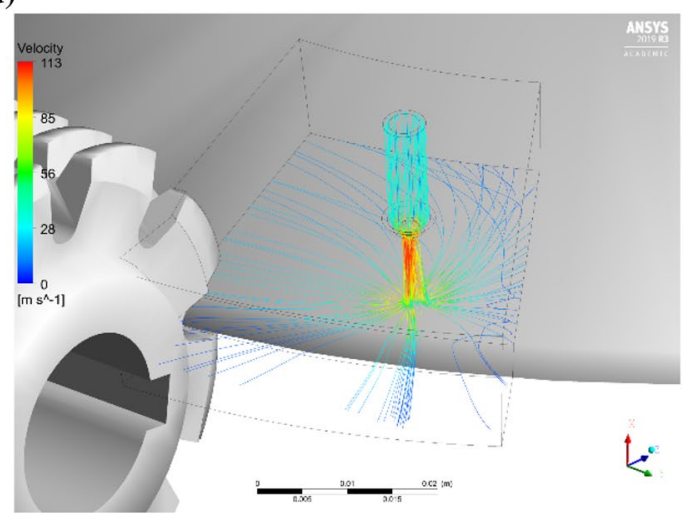

Fig. 8 Layout of air flow streamlines in fluid domain obtained for angle of inclination of nozzle $\varepsilon . \mathbf{a ~} 30^{\circ}, \mathbf{b} 45^{\circ}, \mathbf{c} 60^{\circ}, \mathbf{d} 90^{\circ}$

Table 3 Efficiency $\eta_{w s}$ of air delivery system

\begin{tabular}{l}
\hline $\begin{array}{l}\text { Angle of inclination of nozzle } \\
\varepsilon\left[^{\circ}\right]\end{array}$ \\
\begin{tabular}{llll}
\hline 30 & 45 & 60 & 90 \\
\hline \multicolumn{2}{l}{ Efficiency $\eta_{w s}[-]$} \\
0.287 & 0.282 & 0.236 & 0.158
\end{tabular}
\end{tabular}

easier installation and a shorter time in setting it in position. At the same time, further increasing the angle of tilt of the nozzle causes that the difference in efficiency increases significantly. Indeed, for an angle of $\varepsilon=60^{\circ}$ the $\eta_{w s}$ value is approximately $8 \%$ greater in regard to the efficiency for an angle of $\varepsilon=30^{\circ}$, while this difference reaches $45 \%$ for an angle of $\varepsilon=90^{\circ}$.

\subsection{Wall shear stresses $\tau_{w}$}

Figure 10 presents layouts of wall shear stresses $\tau_{w}$ occurring on the surface of a tapering grinding wheel in the grinding wheel active surface area. Layouts are presented for four angular settings of the nozzle, namely: $30^{\circ}, 45^{\circ}, 60^{\circ}, 90^{\circ}$.

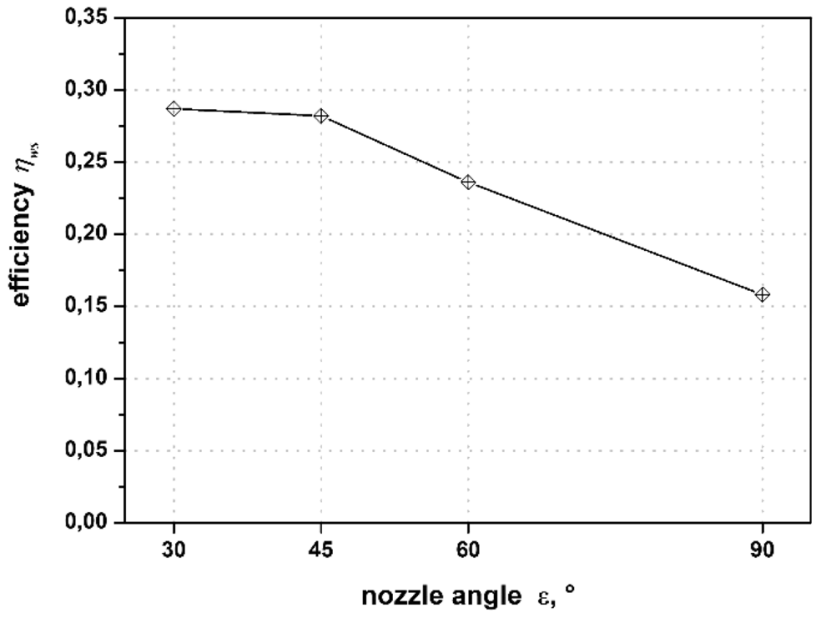

Fig. 9 Efficiency $\eta_{w s}$ of air delivery system obtained for four angles of inclination of nozzle $\varepsilon: 30^{\circ} ; 45^{\circ} ; 60^{\circ} ; 90^{\circ}$

In Table 4 and Fig. 11 maximum values of wall shear stresses $\tau_{w \text {-max }}$ obtained for four angles of inclination of nozzle $\varepsilon$ are presented.

On the basis of the data presented in Table 4 and Fig. 11, it may be stated that the greatest value of wall shear stresses 
(a)

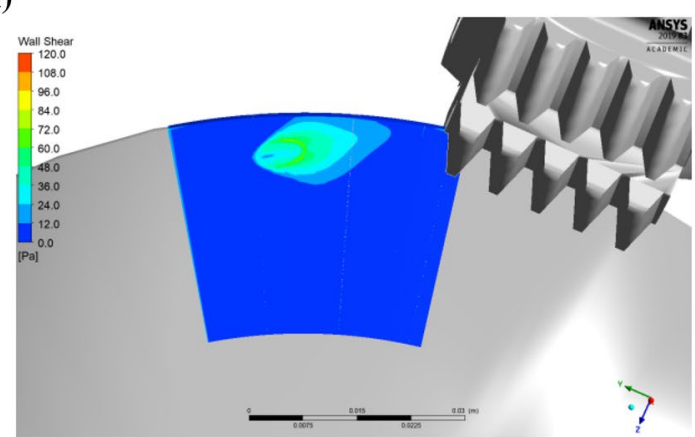

(c)

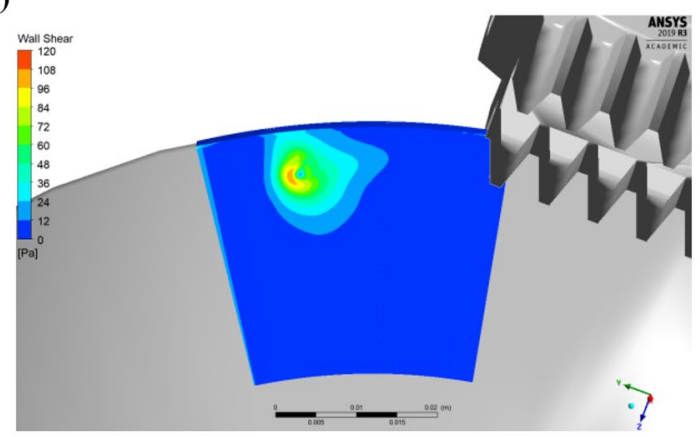

(b)

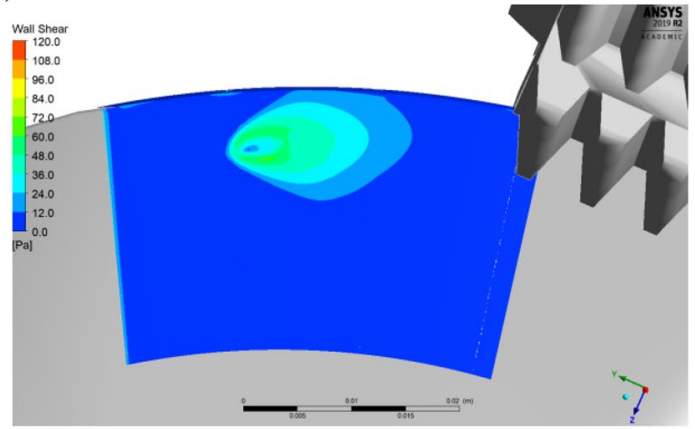

(d)

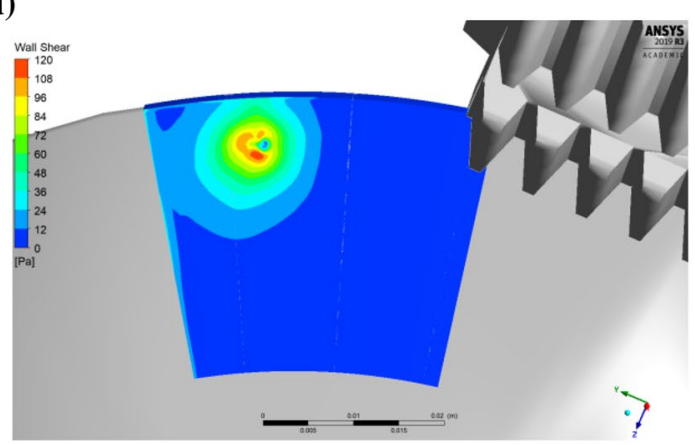

Fig. 10 Layouts of wall shear stresses $\tau_{w}$ obtained for four angles of inclination of nozzle $\varepsilon: 30^{\circ} ; 45^{\circ} ; 60^{\circ} ; 90^{\circ}$

Table 4 Maximum wall shear stress $\tau_{w-\max }$
Angle of inclination of nozzle $\varepsilon\left[^{\circ}\right]$

\begin{tabular}{lll}
\hline 30 & $45 \quad 60 \quad 90$ \\
\hline
\end{tabular}

Maximum wall shear stresses $\tau_{w-\max }[\mathrm{Pa}]$

$\begin{array}{llll}54.0 & 63.9 & 101.3 & 118.4\end{array}$

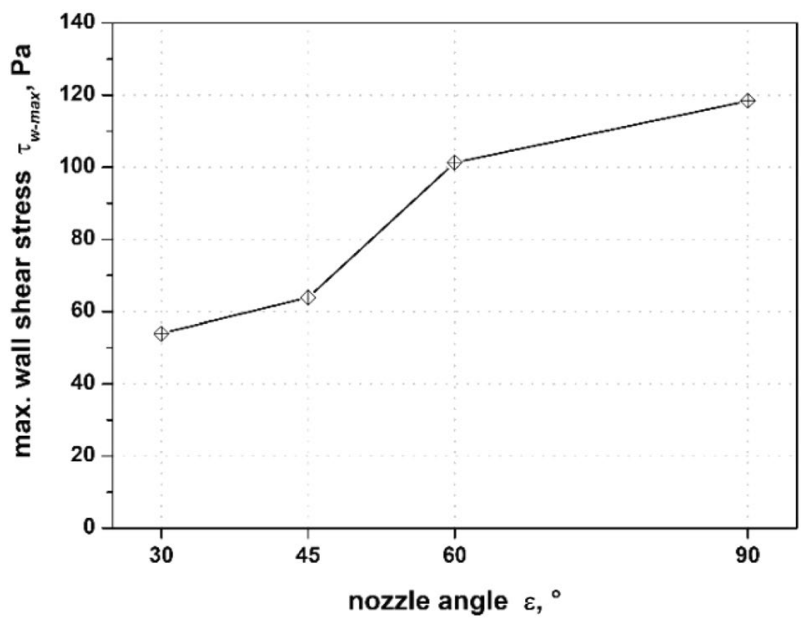

Fig. 11 Maximum wall shear stresses $\tau_{w \text {-max }}$ obtained for four angles of inclination of nozzle $\varepsilon$ : $30^{\circ} ; 45^{\circ} ; 60^{\circ} ; 90^{\circ}$ occurred at an angle of $\varepsilon=90^{\circ}$. At the same time, the maximum $\tau_{w}$ value decreases along with the angle of the spray nozzle in regard to the GWAS, reaching at an angle of $\varepsilon=30^{\circ}$, a value over twice as low as that in relation to the value obtained at an angle of $\varepsilon=90^{\circ}$. This results from the above-mentioned occurrence of the air barrier phenomenon around the spinning grinding wheel which carries the stream of air from the spray nozzle. The lower the value of the angle of inclination of the nozzle, the lower the amount of air reaching the GWAS, while more is delivered to the contact zone of the grinding wheel with the hob cutter.

\subsection{Effect of wall shear stresses $\tau_{w}$ on areas of wall shear stress $\boldsymbol{P}_{\boldsymbol{\tau}}$}

Attention should be paid to the fact that apart from the shear stress value $\tau_{w}$, the areas of wall shear stress $P_{\tau}$ on which these stresses operate also have an impact on the ability to clean impurities from the grinding wheel active surface. The greater the area of wall shear stress, the greater the ability to remove impurities from the surface of the grinding wheel. Table 5 presents the effects of wall shear stresses $\tau_{w}$ on areas of wall shear stress $P_{\tau}$ caused by the stream of air, and determined for four cases of angular settings of the nozzle, namely: $30^{\circ}, 45^{\circ}, 60^{\circ}, 90^{\circ}$. For each of these four angles $\varepsilon$, an area of wall shear stress was selected for 
Table 5 Areas of wall shear stress $P_{\tau}$

\begin{tabular}{|c|c|c|c|c|}
\hline \multirow{3}{*}{$\begin{array}{l}\text { Wall shear stresses } \\
\tau_{w}[\mathrm{~Pa}]\end{array}$} & \multicolumn{4}{|c|}{ Angle of inclination of nozzle $\varepsilon\left[^{\circ}\right]$} \\
\hline & 30 & 45 & 60 & 90 \\
\hline & \multicolumn{4}{|c|}{ Areas of wall shear stress $P_{\tau}\left[\mathrm{mm}^{2}\right]$} \\
\hline $30-120$ & 51.57 & 52.81 & 62.70 & 97.04 \\
\hline $40-120$ & 22.89 & 22.57 & 41.25 & 69.34 \\
\hline $50-120$ & 2.27 & 7.15 & 27.46 & 49.46 \\
\hline
\end{tabular}

analysis determined by three ranges of wall shear stresses, namely: (1) 30-120 Pa, (2) 40-120 Pa and (3) 50-120 Pa.

The shape and size of the area of wall shear stress $P_{\tau}$, obtained depending on the angle of the inclination of the nozzle $\varepsilon$, is depicted in Fig. 12. On this image is shown areas of wall shear stress $P_{\tau}$ obtained for case 1 , where the wall shear stresses were found to be in a range of 30 to $120 \mathrm{~Pa}$. The areas of wall shear stress are shown in green.

With the aim of analysing the results presented in Table 5, their values have been used to create the graph in Fig. 13.

On the basis of Table 5 and Fig. 13 it may be observed that for all three ranges of wall shear stresses $\tau_{w}$ the greatest areas of wall shear stress $P_{\tau}$ were obtained by setting the

(a)

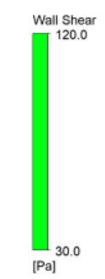

(c)
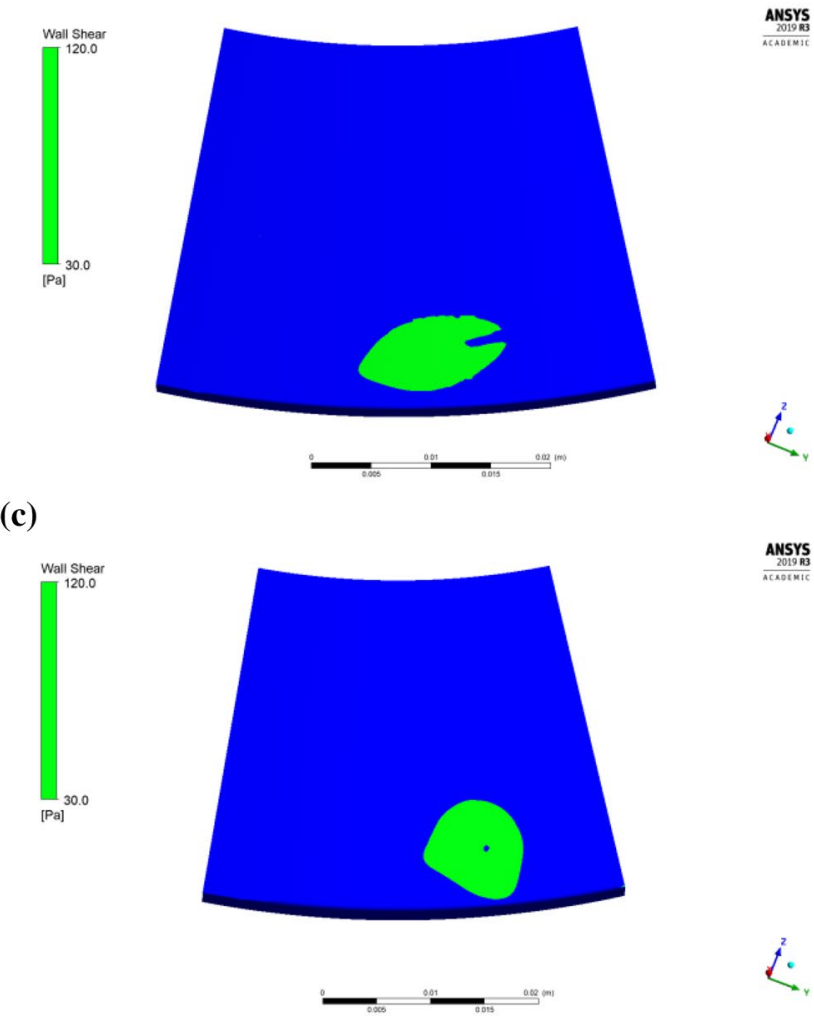

spray nozzle at an angle of $\varepsilon=90^{\circ}$ in regard to the GWAS. It is worth noting that the second highest area of wall shear stress $P_{\tau}$ values occurred by setting the nozzle at an angle of $\varepsilon=60^{\circ}$ and is, on average, about $40 \%$ lower than the highest.

The above-mentioned property results due to the character of the air flow and is caused by the occurrence of the air barrier phenomenon around the spinning grinding wheel, mostly blocking the air stream reaching the GWAS, a phenomenon already described in regard to the efficiency $\eta_{w s}$ graph (Fig. 10), as well as the maximum wall shear stresses $\tau_{w-\max }$ (Fig. 11).

\section{Experimental verification of numerical simulation results}

\subsection{Grinding the face surface of hob cutters}

The aim of the experimental tests was to verify the results of numerical simulations of the air flow used in the grinding zone when employing the MQL method. Due to the fact that one of the functions of coolant is removing chips from the grinding zone, as well as cleaning the grinding wheel itself, the amount of clogging occurring on the

(b)
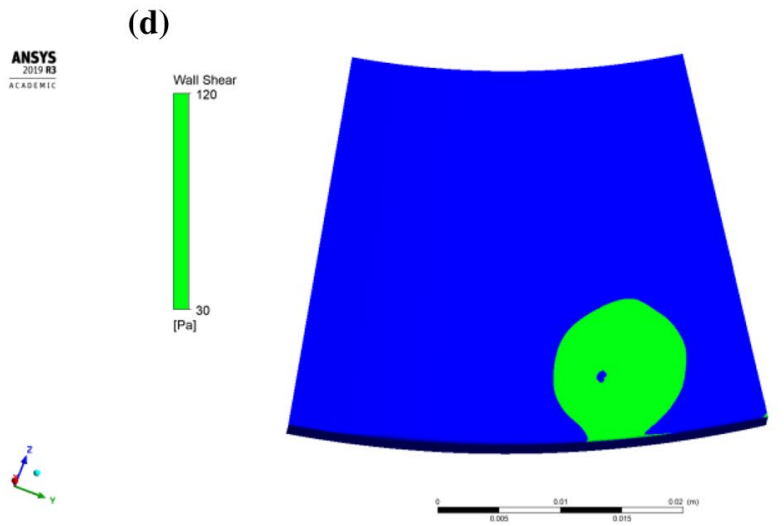

$\frac{\text { ANSYS }}{2019 \text { ह1 }}$

i.

Fig. 12 Areas of wall shear stress $P_{\tau}$ showing occurrence of wall shear stresses $\tau_{w}$ in a range of 30-120 Pa obtained for angles of inclination of nozzle $\varepsilon$. a $30^{\circ}, \mathbf{b} 45^{\circ}, \mathbf{c} 60^{\circ}, \mathbf{d} 90^{\circ}$ 


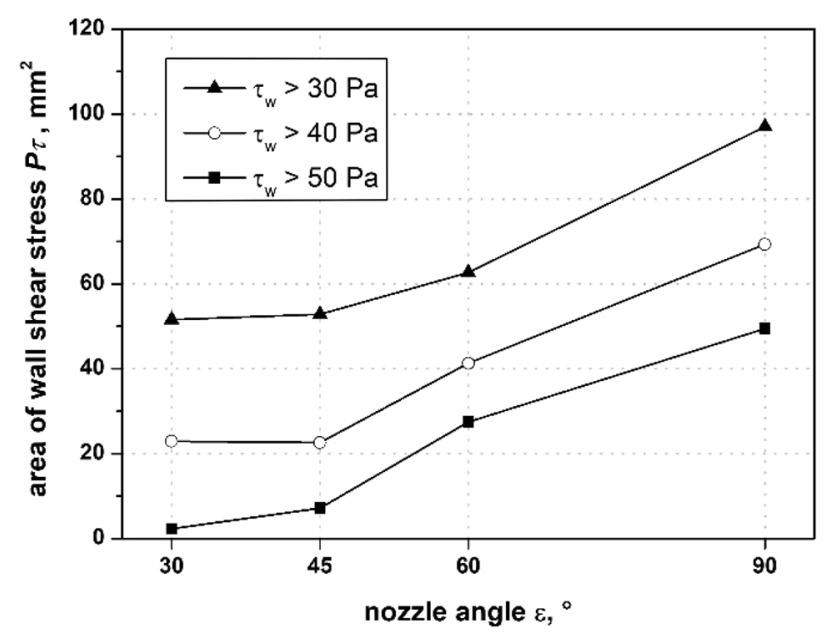

Fig. 13 Areas of wall shear stress $P_{\tau}$ showing occurrence of wall shear stresses $\tau_{w}$ obtained in a range of: a $30-170 \mathrm{~Pa}, \mathbf{b} 40-170 \mathrm{~Pa}$, c $50-170 \mathrm{~Pa}$

grinding wheel active surface was chosen as a parameter verifying the effectiveness of air delivery. During the experimental tests, the face surface of hob cutters was ground, followed by the measurement of the proportion of surface clogging occurring on the grinding wheel active surface, with a grinding wheel clogging coefficient of $Z \%$ being determined on this basis. The obtained results allowed one to assess in a direct manner, the conditions for delivering air in the MQL method determined by the angle of inclination of the spray nozzle $\varepsilon$.
During grinding, the face surface of $\mathrm{NMFc}-3 / 20^{\circ} / \mathrm{B}$ solid hob cutters made of HS6-5-2 high speed uncoated steel was sharpened. These cutters are intended for the manufacture of spur cogwheels in accordance with ISO 53 and ISO 54 norms. Table 6 presents the grinding conditions applied during the described tests.

The hob cutters were sharpened on a special conventional hob grinding machine for sharpening using a Norton 38A60KVBE dish grinding wheel. This is a grinding wheel made of white fused alumina grains with a vitrified bond. The grinding wheel was dressed before each test with the use of a single point diamond dresser. The grinding parameters of the hob cutter blades were selected on the basis of the given literature $[57,58]$, as well as workshop practices.

During testing, coolant was delivered in the form of an oil-mist with the aid of the MQL-type system Micro-Jet MKS-G100, manufactured by MicroJet (Germany) with an output of $Q_{\mathrm{MQL}}=50 \mathrm{ml} / \mathrm{h}$. As a fluid, an ester-based synthetic oil was used, namely Biocut 3000 made by Molyduval (Germany) [59]. The nozzle was tilted in regard to the grinding wheel active surface applying a range of four angles $\varepsilon$, namely: $30^{\circ} ; 45^{\circ} ; 60^{\circ} ; 90^{\circ}$. As a reference, machining was also conducted using the flood method (WET), applying a water-oil emulsion by the use of Emulgol ES-12 (5\%) oil made by Orlen Oil (Poland) [60]. The conditions for applying the oil were set on the basis of previous experiments [10]. A single nozzle was used, titled at an angle of $\varepsilon=30^{\circ}$ in regard to the grinding wheel active surface, which delivered the emulsion into the grinding zone with a nominal output of $Q_{\text {WET-IN }}=7$ 1/min.
Table 6 Grinding conditions

Grinding wheel

Dressing parameters

Grinding parameters

Coolant

Grinding mode

Grinding mode
Grinding machine
Workpiece
Grinding wheel
Dressing parameters
Grinding parameters
Coolant

Hob resharpening

Conventional hob grinding machine

Hob cutter NFMc- $3 / 20^{\circ} / \mathrm{B}$

Material: HS6-5-2 high speed steel, hardened with $62 \pm 1$ HRC $m=3 \mathrm{~mm}, \alpha=20^{\circ}, z_{h}=9$

Accuracy class: B (according to PN-ISO 4468)

Normal ground profile

38A60KVBE

Dish grinding wheel - type 12 (according to PN-ISO 525:2001)

Dimensions: $200 / 90 \times 20 / 2 \times 32$

Single point diamond dresser

$Q_{d}=1.0 \mathrm{kt}$

$n_{s}=2950 \mathrm{rpm}, v_{s}=31 \mathrm{~m} / \mathrm{s}, v_{w}=6.6 \mathrm{~m} / \mathrm{min}, a=0.1 \mathrm{~mm}, 10$ grinding passes with $a_{e l}=0.01 \mathrm{~mm}$

(1) Minimum Quantity Lubrication method (MQL)

MicroJet MKS-G100 - oil-mist generator with single external nozzle Fluid: Biocut 3000

$Q_{M O L}=50 \mathrm{ml} / \mathrm{h}$

$\varepsilon=30^{\circ}, 45^{\circ}, 60^{\circ}, 90^{\circ}$

(2) Flood method (WET)

Fluid: 5\% water solution of Emulgol ES-12 oil

$Q_{\text {WET-IN }}=71 / \mathrm{min}$

$\varepsilon=30^{\circ}, 45^{\circ}, 60^{\circ}, 90^{\circ}$ 


\subsection{Measurement of grinding wheel clogging}

The measurement of grinding wheel clogging was commenced from the recording of images of part of the grinding wheel active surface (GWAS) with the use of a DO Smart 5 MP PRO digital microscope, manufactured by Delta Optical (Poland) [61]. The images were recorded by using Optical Smart Analysis 1.0.5 software with $50 \times$ magnification. The images, recorded in gray scale, were analysed with the aim of discovering clogging and then determining the degree to which chips had clogged the intergranular spaces of the grinding wheel. With this aim in mind, Met-Ilo v.5.1 software, developed at the Technical University of Silesia, was used [62]. This software allows one to discover chips accumulated among the grains of the grinding wheel on the basis of the intensity of light reflected from the chips and from the surface in which they are absent. This difference in the intensity of reflected light is used to separate out areas of the images, depending on setting the colour of pixels corresponding to chips as white and designating the remaining pixels red. As a result of dividing the number of black pixels by the total number of pixels, the grinding wheel clogging coefficient $Z \%$ is determined. The final value of the grinding wheel clogging coefficient $Z \%$ representative of single grinding tests were set as the arithmetical average value of the coefficients determined on the basis of five GWAS images taken in various locations on the circumference of the grinding wheel and occupying approximately $6 \%$ of the area of the GWAS in total [10].

\subsection{Results and discussion}

Table 7 and Fig. 14 present the measurement results for clogging of the grinding wheel active surface during grinding with delivery of coolant as part of the minimum quantity lubrication (MQL) method, as well as the flood methods using an oil-water emulsion. The proportion of clogging is described by applying the grinding wheel clogging coefficient $Z \%$.

As Table 7 and Fig. 14 show, the grinding wheel clogging coefficient $Z \%$ assumes the lowest (most beneficial) value for a nozzle inclination angle of $\varepsilon=90^{\circ}$. Here, it should be noticed that the value of the grinding wheel clogging

Table 7 Grinding wheel clogging coefficient $Z_{\%}$

\begin{tabular}{|c|c|c|c|c|}
\hline \multirow{3}{*}{ Coolant } & \multicolumn{4}{|c|}{ Nozzle inclination angle $\varepsilon\left[^{\circ}\right]$} \\
\hline & 30 & 45 & 60 & 90 \\
\hline & \multicolumn{4}{|c|}{ Grinding wheel clogging coefficient $Z_{\%}[\%]$} \\
\hline MQL & 14.6 & 13.2 & 13.8 & 12.9 \\
\hline WET & 1.8 & 2.2 & 3.9 & 4.2 \\
\hline
\end{tabular}

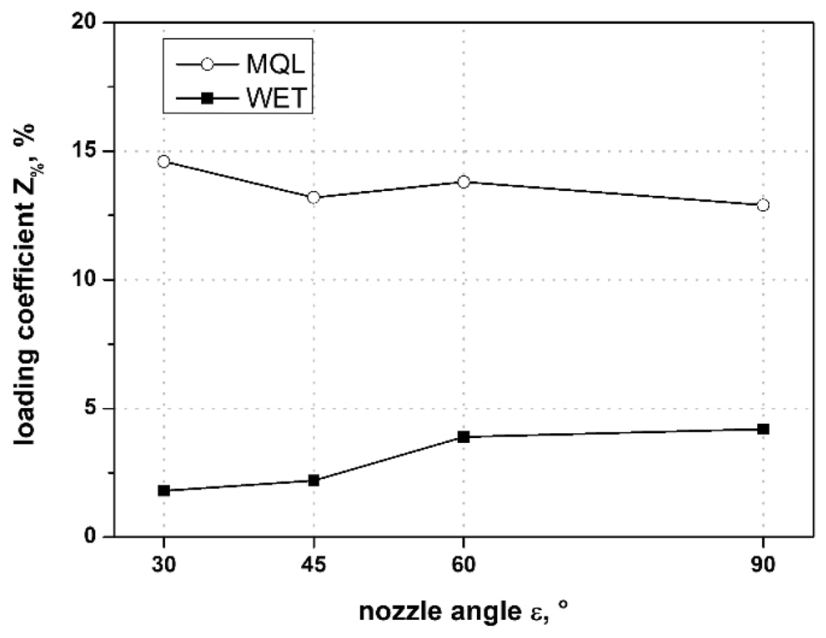

Fig. 14 Grinding wheel clogging coefficient $Z \%$

coefficient $Z \%$ obtained for the remaining angles $\varepsilon$ are similar. The difference in the extreme $Z \%$ values obtained for the angles of $\varepsilon=30^{\circ}$ and $\varepsilon=90^{\circ}$ reach barely 1.7 p.p. Therefore, one may state that a change in the angle $\varepsilon$ does not have a significant impact on the effectiveness of chip removal from the intergranular spaces of the grinding wheel. This property may be explained by analysing the results of numerical simulations and assuming that the impact of air flow delivered into the workpiece/grinding wheel contact zone (expressed as efficiency $\eta_{w s}$ ) on grinding wheel clogging is equivalent to the impact of wall shear stresses $\tau_{w}$ on the GWAS. At an angle of $\varepsilon=90^{\circ}$, wall shear stresses $\tau_{w}$ have a decisive influence on cleaning of the GWAS. With the decreasing the angle of inclination of the nozzle, the impact of shear stresses $\tau_{w}$ also decreases while the cleaning function is taken on by air delivered directly into the contact zone of the grinding wheel with the face surface of the hob cutter being sharpened.

A comparison of the coefficient $Z \%$ obtained during grinding by use of the flood method (WET), as well as the minimum use of machining fluid indicates an insufficient cleaning ability for the MQL method. The difference between the most advantageous coefficient $Z \%$ values obtained from both methods reaches 11.1 p.p., whereby the coefficient $Z \%$ value obtained for the MQL method is more than 7 times greater that the coefficient $Z \%$ value for the WET method.

\section{Conclusions}

The experimental research described in this article concerned determining the ability of air used in the MQL method to clean the grinding wheel active surface (GWAS) during the grinding of the face surface of hob cutters. In 
this regard, a numerical simulation of the cooling and lubrication agent was limited to only providing air, without the involvement of oil. On the basis of the results obtained in regard to the applied conditions of the numerical simulation, it may be seen that the SST $k-\omega$ turbulence model with Kato and Launder's modifications allows one to conduct simulations of the air flow delivered into the grinding zone during sharpening of the hob cutters. However, a detailed analysis is possible to conduct under significantly simplified boundary and initial conditions.

On the basis of an analysis of the numerical simulation of the air flow, it may be stated that:

(1) Decreasing the angle $\varepsilon$ of nozzle inclination in regard to the GWAS increases the directionality of the stream of air causing most of it to be directed into the contact zone of the hob cutter with the grinding wheel. Therefore, the lower the angle $\varepsilon$, the greater the effectiveness of the stream of air from the MQL nozzle reaching the grinding zone, expressing itself as greater efficiency $\eta_{w s}$. The greatest efficiency $\eta_{w s}$ was achieved by setting the nozzle at the lowest of the tested angles, namely $\varepsilon=30^{\circ}$.

(2) Increasing the nozzle inclination angle $\varepsilon$ in regard to the GWAS causes the greater part of the stream of air to reach the surface of the grinding wheel. Thus, the greater the angle $\varepsilon$, the greater the wall shear stresses $\tau_{w}$ on the grinding wheel active surface. The greatest value of maximum wall shear stresses $\tau_{w-\max }$ was obtained for an angle of $\varepsilon=90^{\circ}$.

(3) Increasing the nozzle inclination angle $\varepsilon$ in regard to the GWAS causes the $P_{\tau}$ areas of wall shear stress on which wall shear stresses $\tau_{w}$ exert an impact, to take on the greatest value by setting the spray nozzle at an angle of $\varepsilon=90^{\circ}$.

The results of the experimental tests indicate that:

(1) Changing the nozzle inclination angle $\varepsilon$ did not have a significant impact of the effectiveness of chip removal in the intergranular spaces of the grinding wheel. The difference in the grinding wheel clogging coefficient $Z \%$ between the extreme angular settings of the nozzle $\left(\varepsilon=30^{\circ}\right.$ and $\varepsilon=90^{\circ}$ ) reached barely 1.7 p.p.

(2) The ability of air used in the MQL method to clean the GWAS depends, to the same degree, both on wall shear stresses $\tau_{w}$ and on the amount of air being directed directly into the workpiece/grinding wheel contact zone (expressed as efficiency $\eta_{w s}$ ). By setting the nozzle at an angle of $\varepsilon=90^{\circ}$, wall shear stresses $\tau_{w}$ have a significant impact on cleaning of the GWAS. At an angle of $\varepsilon=30^{\circ}$, the cleaning function is taken on by the air being delivered directly to the contact zone of the grinding wheel with the face surface of the hob cutter being sharpened, expressed quantitatively as efficiency $\eta_{w s}$.

(3) The value of the grinding wheel clogging coefficient $Z_{\%}$ for the MQL method is over 7 times greater than the value of the coefficient value for the flood method (WET). This is indicated by the insufficient ability of the MQL cleaning method to remove impurities from the grinding wheel active surface. A solution to this problem may be the use of an additional nozzle cleaning by the use of compressed air (CA) or cold compressed air (CCA). The latter solution could also fulfil the additional function of cooling the grinding zone.

The conducted tests maybe constitute a basis for optimising the conditions for delivering coolant and lubrication fluids during the process of grinding the face surface of hob cutters applied both in the use of conventional grinding machines, as well as numerically controlled grinding centres.

Funding Not applicable.

\section{Compliance with ethical standards}

Conflict of interest The authors declare that they have no conflict of interest.

Open Access This article is licensed under a Creative Commons Attribution 4.0 International License, which permits use, sharing, adaptation, distribution and reproduction in any medium or format, as long as you give appropriate credit to the original author(s) and the source, provide a link to the Creative Commons licence, and indicate if changes were made. The images or other third party material in this article are included in the article's Creative Commons licence, unless indicated otherwise in a credit line to the material. If material is not included in the article's Creative Commons licence and your intended use is not permitted by statutory regulation or exceeds the permitted use, you will need to obtain permission directly from the copyright holder. To view a copy of this licence, visit http://creativecommons.org/licenses/by/4.0/.

\section{References}

1. Rowe WB (2012) Principles of modern grinding technology, 2nd edn. Elsevier, Oxford

2. Fergani O, Shao Y, Lazoglu I, Liang SY (2014) Temperature effects on grinding residual stress. Proced CIRP 14:2-6

3. Grzesik W, Kruszyński B, Ruszaj A (2010) Surface integrity of machined surfaces. In: Davim JP (ed) Surface integrity in machining. Springer-Verlag, London

4. Kruszyński B, Wójcik R (2001) Residual stress in grinding. J Mater Process Technol 109(3):254-257

5. Jawahir IS, Brinksmeier E, M'Saoubi R, Aspinwall DK, Outeiro JC, Meyer D, Umbrello D, Jayal AD (2011) Surface integrity in material removal processes: Recent advances. CIRP Ann Manuf Technol 60(2):603-626 
6. Debnath S, Reddy MM, Yi QS (2014) Environmental friendly cutting fluids and cooling techniques in machining: a review. J Clean Prod 83:33-47

7. Madanchi N, Kurle D, Winter M, Thiede S, Herrmann C (2015) Energy efficient process chain: The impact of cutting fluid strategies. Proced CIRP 29:360-365

8. Czapiewski W (2017) Methods of minimalization of coolant flow rate in the grinding processes: the Review. J Mech Energy Eng 1(41):117-122

9. Li C, Zhang Q, Wang S, Jia D, Zhang D, Zhang Y, Zhang X (2015) Useful fluid flow and flow rate in grinding: an experimental verification. Int J Adv Manuf Technol 81:785-794

10. Stachurski W, Sawicki J, Krupanek K, Nadolny K (2019) Numerical analysis of coolant flow in the grinding zone. Int J Adv Manuf Technol 104:1999-2012

11. Amiril SAS, Rahim EA, Syahrullail S (2017) A review on ionic liquids as sustainable lubricants in manufacturing and engineering: recent research, performance, and applications. J Clean Prod 168:1571-1589

12. Gajrani KK, Suvin PS, Kailas SV, Sankar MR (2019) Hard machining performance of indigenously developed green cutting fluid using flood cooling and minimum quantity cutting fluid. $\mathrm{J}$ Clean Prod 206:108-123

13. Moraes DL, Garcia MV, Lopes JC, Ribeiro FSF, Sanchez LEA, Foschini CR, Mello HJ, Aguiar PR, Bianchi EC (2019) Performance of SAE 52100 steel grinding using MQL technique with pure and diluted oil. Int J Adv Manuf Technol 105:4211-4223

14. Said Z, Gupta M, Hegab H, Arora N, Khan AM, Jamil M, Bellos E (2019) A comprehensive review on minimum quantity lubrication (MQL) in machining process using nano-cutting fluids. Int $\mathrm{J}$ Adv Manuf Technol 105:2057-2086

15. Sen B, Mia M, Krolczyk GM, Mandal UK, Mondal SP (2019) Eco-friendly cutting fluids in minimum quantity lubrication assisted machining: a review on the perception of sustainable manufacturing. Int J Precis Eng Manuf-Green Technol. https:// doi.org/10.1007/s40684-019-00158-6

16. Grzesik W (2017) Advanced machining processes of metallic materials. Theory, modelling and applications. Elsevier, Amsterdam

17. Srikant RR, Rao PN (2017) Use of vegetable-based cutting fluids for sustainable machining. In: Davim JP (ed) sustainable machining. Springer, Berlin

18. Barczak LM, Batako ADL, Morgan MN (2010) A study of plane surface grinding under minimum quantity lubrication (MQL) conditions. Int J Mach Tools Manuf 50:977-985

19. Kananathan J, Samykano M, Sudhakar K, Subramaniam SR, Selavamani SK, Kumar NM, Keng NW, Kadirgama K, Hamzah WAW, Harun WSW (2018) Nanofluid as coolant for grinding process: an overview. IOP Conf Ser 342:012078. https://doi. org/10.1088/1757-899X/342/1/012078

20. Pervaiz S, Anwar S, Qureshi I, Ahmed N (2019) Recent advances in the machining of titanium alloys using minimum quantity lubrication (MQL) based techniques. Int J Precis Eng Manuf-Green Technol 6:133-145

21. Sawicki J, Kruszyński B, Wójcik R (2017) The influence of grinding conditions on the distribution of residual stress in the surface layer of 17CrNi6-6 steel after carburizing. Adv Sci Technol Res J 11(2):17-22

22. Silva LR, Corrêa ECS, Brandão JR, de Ávila RF (2013) Environmentally friendly manufacturing: Behavior analysis of minimum quantity of lubricant - MQL in grinding process. J Clean Prod. https://doi.org/10.1016/j.jclepro.2013.01.033

23. Sharma VS, Singh G, Sørby K (2015) A review on minimum quantity lubrication for machining processes. Mater Manuf Process 30(8):935-953
24. Iyappan SK, Ghosh A (2020) Small quantity lubrication assisted end milling of aluminium using sunflower oil. Int J Precis Eng Manuf-Green Technol 7:337-345

25. Lawal S, Choudhury I, Nukman Y (2013) A critical assessment of lubrication techniques in machining processes: a case for minimum quantity lubrication using vegetable oil-based lubricant. J Clean Prod 41:201-221

26. Tazehkandi AH, Shabgard M, Pilehvarian F (2015) Application of liquid nitrogen and spray mode of biodegradable vegetable cutting fluid with compressed air in order to reduce cutting fluid consumption in turning Inconel 740. J Clean Prod 108:90-103

27. Madanhire I, Mbohwa C (2016) Mitigating environmental impact of petroleum lubricants. Springer, Switzerland

28. Lopes JC, Garcia MV, Volpato RS, Mello HJ, Ribeiro FSF, Sanchez LEA, Rocha KO, Neto LD, Aguiar PR, Bianchi EC (2020) Application of MQL technique using $\mathrm{TiO}_{2}$ nanoparticles compared to MQL simultaneous to the grinding wheel cleaning jet. Int J Adv Manuf Technol 106:2205-2218

29. Pereira O, Rodriguez A, Barreiro J, López-de-Lacalle LN (2017) Nozzle design for combined use of MQL and cryogenic gas in machining. Int J Precis Eng Manuf-Green Technol 4(1):87-95

30. An Q, Dang J (2020) Cooling effects of cold mist jet with transient heat transfer on high-speed cutting of titanium alloy. Int J Precis Eng Manuf-Green Technol 7:271-282

31. Cai C, Liang X, An Q, Tao Z, Ming W, Chen M (2020) Cooling/ lubrication performance of dry and supercritical $\mathrm{CO}_{2}$-based minimum quantity lubrication in peripheral milling Ti-6Al-4V. Int J Precis Eng Manuf-Green Technol. https://doi.org/10.1007/s4068 4-020-00194-7

32. Abidin ZZ, Mativenga PT, Harrison G (2020) Chilled air system and size effect in micro-milling of nickel-titanium shape memory alloys. Int J Precis Eng Manuf-Green Technol 7:283-297

33. Lopes JC, Garcia MV, Valentim M, Javaroni RL, Ribeiro FSF, Sanchez LEA, Mello HJ, Aguiar PR, Bianchi EC (2019) Grinding performance using variants of the MQL technique: MQL with cooled air and MQL simultaneous to the wheel cleaning jet. Int $\mathrm{J}$ Adv Manuf Technol 105:4429-4442

34. Madanchi N, Zellmer S, Winter M, Flach F, Garnweitner G, Herrmann C (2019) Investigation on the effects of nanoparticles on cutting fluid properties and tribological characteristics. Int J Precis Eng Manuf-Green Technol 6:433-447

35. Stachurski W, Sawicki J, Wójcik R, Nadolny K (2018) Influence of application of hybrid MQL-CCA method of applying coolant during hob cutter sharpening on cutting blade surface condition. J Clean Prod 171:892-910

36. Wang Y, Li C, Zhang Y, Yang M, Li B, Dong L, Wang J (2018) Processing characteristics of vegetable oil-based nanofluid MQL for grinding different workpiece materials. Int J Precis Eng Manuf-Green Technol 5(2):327-339

37. Zhang J, Li C, Zhang Y, Yang M, Jia D, Liu G, Hou Y, Li R, Zhang N, Wu Q, Cao H (2018) Experimental assessment of an environmentally friendly grinding process using nanofluid minimum quantity lubrication with cryogenic air. J Clean Prod 193:236-248

38. Benedicto E, Carou D, Rubio EM (2017) Technical, economic and environmental review of the lubrication/cooling systems used in machining processes. Proced Eng 184:99-116

39. Su Y, Gong L, Chen D (2016) Dispersion stability and thermophysical properties of environmentally friendly graphite oil-based nanofluids used in machining. Adv Mech Eng 8(1):1-11

40. Uysal A, Demiren F, Altan E (2015) Applying minimum quantity lubrication (MQL) method on milling of martensitic stainless steel by using nano $\mathrm{MoS}_{2}$ reinforced vegetable cutting fluid. Proced Soc Behav Sci 195:2742-2747

41. Jadhav ML, Borse SC (2016) Effect of nano fluid in high speed machining of metals: a review. Int J Sci Res Dev 4(4):774-776 
42. Shokoohi Y, Shekarian E (2016) Application of nanofluids in machining processes: a review. J Nanosci Nanotechnol 2(1):59-63

43. Lopes JC, Fragoso KM, Garcia MV, Ribeiro FSF, Francelin AP, Sanchez LEA, Rodrigues AR, Mello HJ, Aguiar PR, Bianchi EC (2019) Behavior of hardened steel grinding using MQL technique under cold air and MQL CBN wheel cleaning. Int J Adv Manuf Technol 105:4373-4387

44. Stachurski W, Krupanek K, Januszewicz B, Rosik R, Wójcik R (2018) An effect of grinding on microhardness and residual stress in $20 \mathrm{MnCr} 5$ following single-piece flow low-pressure carburizing. J Mach Eng 18(4):73-85

45. Hadad MJ, Tawakoli T, Sadeghi MH, Sadeghi B (2012) Temperature and energy partition in minimum quantity lubrication-MQL grinding process. Int J Mach Tools Manuf 54-55:10-17

46. Wu W, Li C, Yang M, Zhang Y, Jia D, Hou Y, Li R, Cao H, Han $Z$ (2019) Specific energy and $G$ ratio of grinding cemented carbide under different cooling and lubrication conditions. Int $\mathrm{J}$ Adv Manuf Technol 105:67-82

47. Morgan MN, Barczak L, Batako A (2012) Temperature in fine grinding with minimum quantity lubrication (MQL). Int J Adv Manuf Technol 60:951-958

48. Adibi H, Rezaei SM, Sarhan AAD (2014) Investigation on using high-pressure fluid jet in grinding process for less wheel loaded areas. Int J Adv Manuf Technol 70:2233-2240

49. Gopan V (2016) Quantitative analysis of grinding wheel loading using image processing. Proced Technol 25:885-891

50. Stachurski W, Nadolny K (2018) Influence of the condition of the surface layer of a hob cutter sharpened using the MQL-CCA hybrid method of coolant provision on its operational wear. Int $\mathbf{J}$ Adv Manuf Technol 98:2185-2200

51. Catalogue (2020) NORTON.SAINT-GOBAIN 2020. www.norto nabrasives.com. 02 Jan 2020.

52. MicroJet (2020) Lubricant tank. https://microjet.de/en/microjettank.html. Accessed 18 Feb 2020.

53. Menter FR (1994) Two-equation eddy-viscosity turbulence models for engineering applications. AIAA J 32(8):1598-1605

54. Kato M, Launder BE (1993) The modeling of turbulent flow around stationary and vibrating square cylinders. In: Proceedings of the 9th Symposium on Turbulent Shear Flows. Kyoto, Japan, pp: 10.4.1-10.4.6.

55. Katritsis D, Kaiktsis L, Chaniotis A, Pantos J, Efstathopoulos EP, Marmarelis V (2007) Wall shear stress: theoretical considerations and methods of measurement. Prog Cardiovasc Dis 49(5):307-329

56. Liu X, Li Z, Gao N (2018) An improved wall shear stress measurement technique using sandwiched hot-film sensors. Theor Appl Mech Lett 8(2):137-141

57. Bianco G (2004) Gear hobbing. Novaprint, Bologna

58. Hall H (2007) Tool and Cutter Sharpening. Special Interest Model Books Ltd, Hemel Hempstead

59. Molyduval (2017) Bicut 3000. http://www.molyduval.com/index .php?module $=$ explorer\%20displayAction $=$ download=datenblaet ter_cd/en/msds/biocut $\% 203000 \% 20 \mathrm{msds}$.pdf. Accessed $18 \mathrm{Feb}$ 2020.

60. Orlen Oil (2020) Emulgol ES-12. www.orlenoil.pl/oodownload/ pds/en/27435. Accessed 18 Feb 2020.

61. Delta Optical (2020) deltaoptical. http://deltaoptical.pl/mikro skop-cyfrowy-delta-optical-smart-5mp-pro?pdf=1. Accessed 18 Feb 2020.

62. Michalska J, Chmiela B (2014) Phase analysis in duplex stainless steel: comparison of EBSD and quantitative metallography methods. IOP Conf Ser 55:012010. https://doi.org/10.1088/1757$899 X / 55 / 1 / 012010$

Publisher's Note Springer Nature remains neutral with regard to jurisdictional claims in published maps and institutional affiliations.

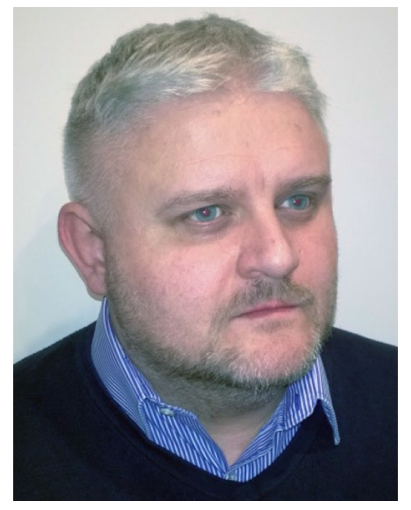

Wojciech Stachurski is the Head of Division of Machining Processes and Tools at the Institute of Machine Tools and Production Engineering at Lodz University of Technology (LUT), Poland. He received an M.Sc. degree in Mechanical Engineering (2001) and Ph.D. degree in Machine Design and Operation (2008) from Lodz University of Technology. Since 2003 he has been a researcher in the Institute of Machine Tools and Production Engineering at LUT, where currently he works as an assistant professor. He has participated in 4 national research projects. $\mathrm{He}$ has published 2 monographs and more than 60 scientific papers in various international and national journals. He is also the co-author of 2 national patents and 3 patent applications. His scientific interests focus on abrasive processes, technological surface layer as well as wear and durability of cutting tools.

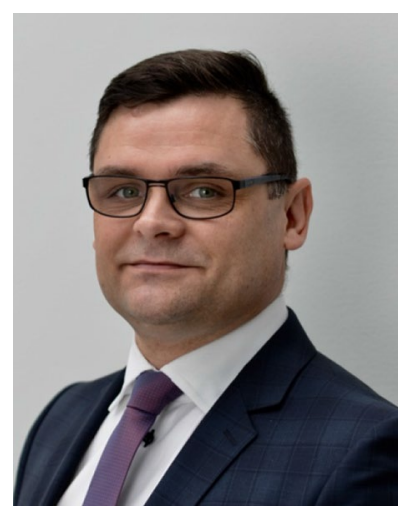

Jacek Sawicki is a Director for Education Affairs and Head of Division of Numerical Method in Materials Science at the Institute of Materials Science and Engineering at Lodz University of Technology (LUT). He is a member of University Council LUT. He received an M.Sc. (1999) and Ph.D. degree (2003) in Materials Science and Engineering from LUT. In 2013 he acquired a post-doctoral degree and currently he is an Associate Professor of the LUT. He is an author or co-author of more than 110 scientific papers and co-inventor of 4 patents, management of 2 projects and contractor of 17 projects. At present, the primary application of his work is in the numerical optimization of surface treatment and thermo-chemical processes, design and computational analysis of medical implants.

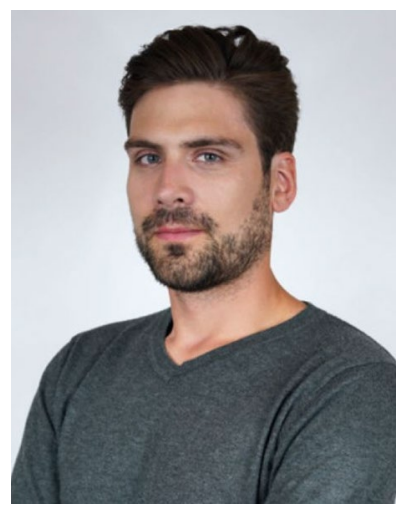

Krzysztof Krupanek is currently working as research assistant and pursuing Ph.D. at the Institute of Material Science and Engineering at Lodz University of Technology. He received an M.Sc. degree in Energy Engineering (2016) from AGH University of Science and Technology. Since then he worked on various projects related to numerical simulations of flow phenomena and material structure. 


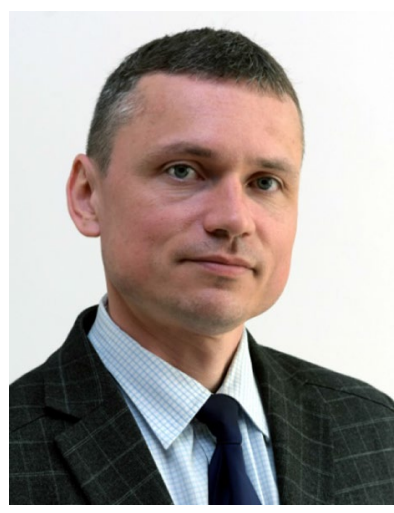

Krzysztof Nadolny received his M.Sc. degree in Mechanics and Machine Design and next the Ph.D (with honors) as well as D.Sc. degree in Machinery Construction and Operation from the Koszalin University of Technology, in 2001, 2006 and 2013, respectively. Since 2006 , he has been a researcher in the Department of Production Engineering at the Koszalin University of Technology, where currently he works as a head of department. His scientific interests focus on problems concerning machining processes and tools, efficiency, monitoring and diagnostics of machining processes as well as tribology. He has participated in 2 international and 3 national research projects, presenting results of his work at 10 international and 21 national conferences, published more than 230 scientific papers in international and national journals, book chapters, as well as conference proceedings. He is also the author of 6 monographs and 13 national patents. 